\title{
A Statistical Approach to the Processing of Metonymy
}

\author{
Masao Utiyama, Masaki Murata, and Hitoshi Isahara \\ Communications Research Laboratory, MP'l, \\ 588-2, Iwaoka, Nishi-ku, Kobe, Hyogo 651-2492 Japan \\ \{mutiyama,murata,isahara\}@crl.go.jp
}

\begin{abstract}
This paper describes a statistical approach to the interpretation of metonymy. A metonymy is received as an input, then its possible interpretations are ranked by applying a statistical measure. 'The method has been tested experinentally. It correctly interpreted 53 out of 75 metonymies in Japanese.
\end{abstract}

\section{Introduction}

Metonymy is a figure of speech in which the name of one thing is substituted for that of something to which it is related. 'Lhe explicit term is 'the name of one thing' and the implicit term is 'the name of sometling to which it is related'. $\Lambda$ typical example of metonymy is

$$
\text { He read Shakespeare. }
$$

'Shakespeare' is substituted for "the works of Shakespeare'. 'Shakespeare' is the explicit term and 'works' is the implicit term.

Metonymy is pervasive in natural language. 'The correct treatment of metonymy is vital for natural language processing applications, especially for machine translation (Kannei and Wakao, 1992; Fass, 1997). A metonymy may be acceptable in a source language but unacceptable in a target language. For example, a direct translation of 'he read Mao', which is acceptable in English and Japanese, is completely unacceptable in Chinese (Kamei and Wakao, 1992). In such cases, the machine translation system has to interpret metonymies to generate acceptable translations.

Previous approaches to processing metonymy have used hand-constructed ontologies or semantic networks (Fass, 1988; Iverson and Helmreich, 1992; Bouaud et al., 1996; Fass, 1997). ${ }^{1}$

\footnotetext{
${ }^{1}$ As for metaphor processing, Ferrari (1996) used tex-
}

Such approaches are restricted by the knowledge bases they use, and may only be applicable to domain-specific tasks because the construction of large knowledge bases could be very difficult.

The method outlined in this paper, on the other hand, uses corpus statistics to interpret metonymy, so that a variety of metonymies can be handled without using hand-constructed knowledge bases. The method is quite promising as shown by the experimental results given in section 5 .

\section{Recognition and Interpretation}

'T'wo main steps, recognition and interpretation, are involved in the processing of metonyny (Fass, 1997). In the recognition step, metonymic expressions are labeled. In the interpretation step, the meanings of those expressions are interpreted.

Sentence (1), for example, is first recognized as a metonymy and 'Shakespeare' is identified as the explicit term. 'The interpretation 'works' is solected as an implicit torm and 'Shakespeare' is replaced by 'the works of Shakespeare'.

A comprehensive survey by Fass (1997) shows that the most common method of recognizing motonymies is by selection-restriction violations. Whether or not statistical approaches canl recognize metonymy as well as the selectionrestriction violation method is an interesting question. Our concern here, however, is the interpretation of metonymy, so we leave that question for a future work.

In interpretation, an implicit term (or terms) that is (are) related to the explicit term is (are) selected. The method described in this paper uses corpus statistics for interpretation.

tual ches obtained through corpus analysis for detecting metaphors. 
This method, as applied to Japanese metonymies, receives a metonymy in a phrase of the form 'Noun $A$ Case-Marker $R$ Predicate $V '$ and returns a list of nouns ranked in order of the system's estimate of their suitability as interpretations of the metonymy, assuming that noun $A$ is the explicit term. For example, given Ford ${ }^{2}$ wo (accusative-case) kau (buy) (buy a Ford), zyôyôsya (car), best seller, kuruma (vehicle), etc. are returned, in that order.

The method follows the procedure outlined below to interpret a metonymy.

1. Given a metonymy in the form 'Noun $A$ Case-Marker $R$ Predicate $V$ ', nouns that can be syntactically related to the explicit term $A$ are extracted from a corpus.

2. The extracted nouns are ranked according to their appropriateness as interpretations of the metonymy by applying a statistical measure.

The first step is discussed in section 3 and the second in section 4 .

\section{Information Source}

We use a large corpus to extract nouns which can be syntactically related to the explicit term of a metonymy. A large corpus is valuable as a source of such nouns (Church and Hanlks, 1990; Brown et al., 1992).

We used Japanese noun phrases of the form $A$ no $B$ to extract nouns that were syntactically related to $A$. Nouns in such a syntactic relation are usually close semantic relatives of each other (Murata of al., 1999), and occur relatively infrequently. We thus also used an $A$ near $B$ relation, i.e. identifying the other nouns within the target sentence, to extract nouns that may be more loosely related to $A$, but occur more frequently. These two types of syntactic relation are treated differently by the statistical measure which we will discuss in section 4 .

The Japanese noun phrase $A$ no $B$ roughly corresponds to the English noun phrase $B$ of $A$, but it has a much broader range of usage (Kurohashi and Sakai, 1999). In fact, $A$ no $B$ can express most of the possible types of semantic relation between two nouns including metonymic

\footnotetext{
${ }^{2}$ 'Ford' is spelled 'hôdo' in Japanese. We have used English when we spell Japanese loan-words from English for the sake of readability.
}

concepts such as that the name of a container can represent its contents and the name of an artist can imply an artform (container for contents and artist for artform bolow). ${ }^{3} \mathrm{Ex}$ amples of these and similar types of metonymic concepts (Lakoff and Johnson, 1980; Fass, 1997) are given below.

\section{Container for contents}

- glass no mizu (water)

- nabe (pot) no ryôri (food)

\section{Artist for artform}

- Beethoven no kyoku (music)

- Picasso no e (painting)

\section{Object for user}

- ham sandwich no kyaku (customer)

- sax no sôsya (performer)

\section{Whole for part}

- kuruma (car) no tire

- door no knob

These examples suggest that we can extract semantically related nouns by using the $A$ no $B$ relation.

\section{Statistical Measure}

A metonymy 'Noun $A$ Case-Marker $R$ Predicate $V$ ' can be regarded as a contraction of 'Noun $A$ Syntactic-Rclation $Q$ Noun $B$ CaseMarker $R$ Predicate $V$ ', where $A$ has relation $Q$ to $B$ (Yamamoto et al., 1998). For example, Shakespeare wo yomu (read) (read Shakespeare) is regarded as a contraction of Shakespeare no sakuhin (works) wo yomu (read the works of Shakespeare), where $A=$ Shakespeare, $Q=$ no, $B=$ sakuhin, $R=w o$, and $V=y o m u$.

Given a metonymy in the form $A R V$, the appropriateness of noun $B$ as an interpretation of the metonymy under the syntactic relation $Q$ is defined by

$$
L_{Q}(B \mid A, R, V) \doteq \operatorname{Pr}(B \mid A, Q, R, V)
$$

\footnotetext{
${ }^{3}$ Yamamoto et al. (1998) also used $A$ no $B$ relation to interpret metonymy.
} 
where $\operatorname{Pr}(\cdots)$ represents probability and $Q$ is either an $A$ no $B$ relation or an $A$ near $B$ relation. Next, the appropriateness of noun $B$ is defined by

$$
M(B \mid A, R, V) \doteq \max _{Q} L_{Q}(B \mid A, R, V) .
$$

We rank nouns by applying the measure $M$.

Equation (2) can be decomposed as follows:

$$
\begin{aligned}
L_{Q}(B \mid A, R, V) & \operatorname{Pr}(B \mid A, Q, R, V) \\
= & \frac{\operatorname{Pr}(A, Q, B, R, V)}{\operatorname{Pr}(A, Q, R, V)} \\
= & \frac{\operatorname{Pr}(A, Q, B) \operatorname{Pr}(R, V \mid A, Q, B)}{\operatorname{Pr}(A, Q) \operatorname{Pr}(R, V \mid A, Q)} \\
\simeq & \frac{\operatorname{Pr}(B \mid A, Q) \operatorname{Pr}(R, V \mid I 3)}{\operatorname{Pr}(R, V)}
\end{aligned}
$$

where $\langle A, Q\rangle$ and $\langle R, V\rangle$ are assumed to be independent of each other.

Let $f(e v e n t)$ be the frequency of an event and Classes (B) be the set of semantic classes to which $B$ belongs. 'l'he expressions in Equation (4) are then defined by ${ }^{4}$

$$
\operatorname{Pr}(B \mid A, Q) \doteq \frac{f(A, Q, B)}{f(A, Q)}=\frac{f(A, Q, B)}{\sum_{B} f(A, Q, B)},
$$

$$
\begin{aligned}
& \operatorname{Pr}(R, V \mid B)
\end{aligned}
$$

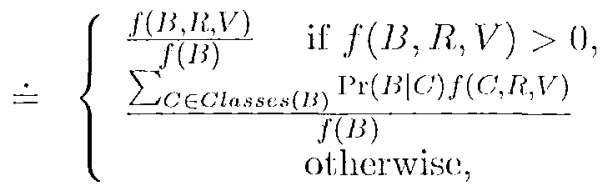

$$
\begin{aligned}
& \operatorname{Pr}(B \mid C) \doteq \frac{f(B) /|C l a s s e s(B)|}{f(C)} .
\end{aligned}
$$

We onitted $\operatorname{Pr}(R, V)$ from Equation (4) when wo calculated Equation (3) in the experiment described in section 5 for the sake of simplicity.

\footnotetext{
${ }^{4}$ Strictly speaking, Equation (6) does not satisfy $\sum_{R, V} \operatorname{Pr}(R, V \mid B)=1$. Wo have adopted this definition for the sake of simplicity. This simplification has little effect on the final results because $\sum_{C \in \text { Classes( }(B)} \operatorname{Pr}(B \mid C) f(C, R, V) \ll 1$ will usually holk. More sophisticated methors (Manning and Schïtzc, 1999) of smoothing probability distribution may be beneficial. However, applying such methods and companing their eflects on the interpretation of metonymy is beyond the scope of this paper.
}

This treatment does not alter the order of the nouns ranked by the system because $\operatorname{Pr}(R, V)$ is a constant for a given metonymy of the form $A R, V$.

Equations (5) and (6) diffor in their treatment of zero frequency nouns. In Equation (5), a noun $B$ such that $f(A, Q, B)=0$ will be ignored (assigned a zero probability) because it is unlikely that such a noun will have a close relationship with noun $A$. In Equation (6), on the other hand, a noun $B$ such that $f(B, R, V)=0$ is assigned a non-zero probability. These treatments reflect the asymmetrical property of metonymy, i.e. in a metonymy of the form $A R V$, an implicit term $B$ will have a much tighter relationship with the explicit term $A$ than with the predicate $V$. Consequently, a noun $B$ such that $f(A, Q, B) \gg 0 \wedge f(B, R, V)=0$ may be alppropriate as an interpretation of the metonymy. Therefore, a non-zero probability should be assigned to $\operatorname{Pr}(R, V \mid B)$ even if $f(B, R, V)=0 .{ }^{5}$

Equation (7) is tho probability that noun $B$ occurs as a member of class $C$. This is reduced to $\frac{f(I))}{f(C)}$ if $B$ is not ambiguous, i.c. $\mid$ Classes $(B) \mid=$ 1. If it is ambiguous, then $f(B)$ is distributed equally to all classes in Classes $(B)$.

The frequency of class $C$ is obtained similarly:

$$
f(C)=\sum_{B \in C} \frac{f(B)}{|\operatorname{Classes}(B)|},
$$

where $B$ is a noun which belongs to the class $C$. Finally we derive

$$
f(C, R, V)=\sum_{B \in C} \frac{f(B, R, V)}{|\operatorname{Classes}(B)|} .
$$

In summary, we use the measure $M$ as defincd in Equation (3), and calculated by applying Equation (4) to Equation (9), to rank nomiss according to their appropriateness as possible interpretations of a metonymy.

Example Given the statistics below, bottle wo akeru (open) (open a bottle) will be interpreted

\footnotetext{
${ }^{5}$ The use of Equation (6) takes into account a noun $B$ such that $f(B, R, V)=0$. But, such a noun is usually ignored if there is another noun $B^{\prime}$ such that $f\left(B^{\prime}, R, V\right)>$ 0 because $\sum_{C \in C \text { asses( } B)} \operatorname{Pr}(B \mid C) f(C, R, V) \ll 1 \leq$ $f\left(B^{\prime}, R, V\right)$ will usually hold. 'This means that the cooccurrence probability between implicit terms and verbs are also important in eliminating inappropriate nouns.
} 
as described in the following paragraphs, assuming that cap and reizoko (refrigerator) are the candidate implicit terms.

Statistics:

$$
\begin{aligned}
f(\text { bottle, no, cap }) & =1, \\
f(\text { bottle, no, reizoko }) & =0, \\
f(\text { bottle, no }) & =2, \\
f(\text { bottle, ncar, cap }) & =1, \\
f(\text { bottle, near, reizôko }) & =2, \\
f(\text { bottle, near }) & =503, \\
f(\text { cap }) & =478, \\
f(\text { reizôko }) & =1521, \\
f(\text { cap, wo, akeru }) & =8, \text { and } \\
f(\text { reizoko, wo, akeru }) & =23 .
\end{aligned}
$$

$f(b o t t l e, n o$, reizokko $)=0$ indicates that bottle and reizôko are not close semantic relatives of each other. 'This shows the effectiveness of using $A$ no $B$ relation to filter out loosely related words.

Measure:

$$
\begin{aligned}
& L_{n o}(c a p)=\frac{f(\text { bottle, }, \text { no, cap })}{f(\text { bottle }, \text { no })} \\
& \times \frac{f(\text { cap }, w o, a k c r u)}{f(c a p)} \\
& =\frac{1}{2} \frac{8}{478}=8.37 \times 10^{-3}, \\
& L_{\text {near }}(\text { cap })=\frac{f(\text { bottle, near }, \text { cap })}{f(\text { bottle }, \text { near })} \\
& \times \frac{f(\text { cap }, \text { wo, aker } u)}{f(\text { cap })} \\
& =\frac{1}{503} \frac{8}{478}=3.33 \times 10^{-5}, \\
& L_{n o}(\text { reizôko })=\frac{f(\text { bottle }, \text { no, reizôko })}{f(\text { bottle }, \text { no })} \\
& \times \frac{f(\text { reizôko, wo, akeru })}{f(\text { reizôko })} \\
& =\frac{0}{2} \frac{23}{1521}=0 \\
& L_{\text {near }}(\text { reizôko })=\frac{f(\text { bottle }, \text { near }, \text { reizôko })}{f(\text { bottle }, \text { near })} \\
& \times \frac{f(\text { reizôko, wo, akeru })}{f(\text { reizôko })}
\end{aligned}
$$

$$
=\frac{2}{503} \frac{23}{1521}=6.01 \times 10^{-5},
$$

$$
\begin{aligned}
& M(\text { cap }) \\
& \quad=\max \left\{L_{n o}(\text { cap }), L_{\text {near }}(\text { cap })\right\} \\
& =8.37 \times 10^{-3}, \text { and } \\
& M(\text { reizôko }) \\
& \quad=\max \left\{L_{n o}(\text { reizôko }), L_{\text {near }}(\text { reizôko })\right\} \\
& =6.01 \times 10^{-5},
\end{aligned}
$$

where $L_{n o}(c a p)=L_{n o}($ cap $\mid$ bottle, wo, akeru $)$, $M(c a p)=M($ cap $\mid$ bottle, wo, akeru $)$, and so on.

Since $M($ cap $)>M($ reizôko $)$, wo can conclude that cap is a more appropriate implicit term than reizokko. This conclusion agrees with our intuition.

\section{Experiment}

\subsection{Material}

Metonymies Seventy-five metonymies were used in an experiment to test the proposed method. Sixty-two of them were collected from literature on cognitive linguistics (Yamanashi, 1988; Yamanashi, 1995) and psycholinguistics (Kusumi, 1995) in Japanese, paying attention so that the types of metonymy were sufficiently diverse. The remaining 13 metonymies were direct translations of the English metonymies listed in (Kamei and Wakao, 1992). 'These 13 metonymies are shown in Table 2, along with the results of the experiment.

Corpus A corpus which consists of seven years of issues of the Mainichi Newspaper (from 1991 to 1997 ) was used in the experiment. Tho sentences in the corpus wore morphologically analyzed by ChaSen version 2.0b6 (Matsumoto et al., 1999). The corpus consists of about 153 million words.

Semantic Class A Japanese thesaurus, Bunrui Goi-Hyô (The National Language Rescarch Institute, 1996), was used in the experiment. It has a six-layered hierarchy of abstractions and contains more than 55,000 nouns. A class was defined as a set of nouns which are classified in the same abstractions in the top three layers. The total number of classes thus obtained was 43. If a noun was not listed in the thesaurus, it was regarded as being in a class of its own. 


\subsection{Method}

The method we have described was applied to the metonymies described in section 5.1. The procedure described below was followed in interpreting a metonyny.

1. Given a metonymy of the form 'Nomn $A$ Casc-Marker $R$ Predicatio $V$, nomus rolated to $A$ by $A$ no $B$ relation and $/$ or $A$ near 13 relation were extracted from the corpus described in Section 5.1.

2. The extiracted nouns (candidates) were ranked according to the mosisure $M$ eledined in Equation (3).

\subsection{Results}

The result of applying the proposed method to our set of metonymies is summarized in 'Jable 1. A reasonably good result can be seen for 'both relations', i.e. the result obtained by using both $A$ no $B$ and $A$ necar $B$ redations when extracting noums fiom the corpus. The acenracy of 'both relations', the ratio of the $1111 \mathrm{~m}$ ber of correctly interpreted ${ }^{(6)}$ top-ranked canclidatios to the total number of metonymics in our sot, was $0.71(-533 /(53+22))$ and the $95 \%$ confidence interval estimate was botwon 0.61 and 0.81 .

We regard this result as quite promising. Since the metonymies wo used were gencral, domain-independent ones, the degree of acenracy achered in this experiment is likely to be repeated when our method is apjulied to other general sets of netonyunies.

Lable 1: Experimential results.

\begin{tabular}{|l|cc|}
\hline Relations used & Correct & Wrong \\
\hline Both rolations & 53 & 22 \\
Only A no B & 50 & 25 \\
Only A near B & 43 & 32 \\
\hline
\end{tabular}

Table 1 also shows that 'botle relations' is more accurate them either the result obtained by solely using the $A$ no $B$ relation or the $A$ near $B$ relation. 'The use of multiple relations in metonymy interpretation is thus seen to be: beneficial.

\footnotetext{
Grithe correctness was judged by the authors. $A$ candidate was judged correct when it made sense in Japanese. For example, we regarded beer; cola, and miza (water) as all correct interpretations for glass wo nomu (drink) (drink a glass) because they made sense in some context.
}

Table 2 shows the results of applying the method to the thirteen directly translated metonymies described in section 5.1. Asterisks $(*)$ in the first column inclicate that direct translation of the sentences result in unaceptable Japanese. The C's and W's in the second column respectively indicate that the topranked candidates were correct and wrong. 'The sentences in the thired columm are the original English metonymies aclopted from (Kannei and Wakao, 1992). The Japancse metonymies in the form 'noun case-marker predicate" ${ }^{7}$, in the fourth columm, are the inputs to the methosl. In this column, wo and ga mainly represent the accusative-case and nominative-case, respectively. The nouns listed in the last column are the top three canclidates, in order, according to the moasure $M$ that was defined in Equation (3).

'lhese results demonstrate the effectiveness of the method. 'I'en ont of the 1.3 motonymics were interpreted correctly. Morcover, if wo restrict onr attention to the ten motonymins that are acceptable in Japanese, all but one were interpreted correctly. The acenracy was $0.9=(9 / 10)$, higher than that for "both relations' in 'Table 1. The reason for the higher degree of accuracy is that the motonymies in table 2 are somewhat typical and relatively casy to interpert, while the metonymies collected from Japanese solures included a diversity of types and were more difficult to interpret.

Finally, the effectiveness of using semantic chasses is discussed. 'The top candidates of six out of the 75 metonymies were assigned thein appropriateness by using their semantic classes, i.e. the values of the measure $M$ was calculated with $f(B, R, V)=0$ in Equation (6). Of these, three were correct. On the other hand, if semantic class is not used, then three of the six are still correct. Here there was no inprovement. However, when we surveyed the results of the whole experiment, we found that nouns for which $f(B, R, V)=0$ often had close relationship) with explicit terms in metonymies and were appropriate as interpretations of the metonymies. We need more research before wo can judge the effectiveness of utilizing semantic classes.

\footnotetext{
${ }^{7}$ Predicates are lemmatized.
} 
Table 2: Results of applying the proposed method to direct translations of the metonymies in (Kamei and Wakao, 1992).

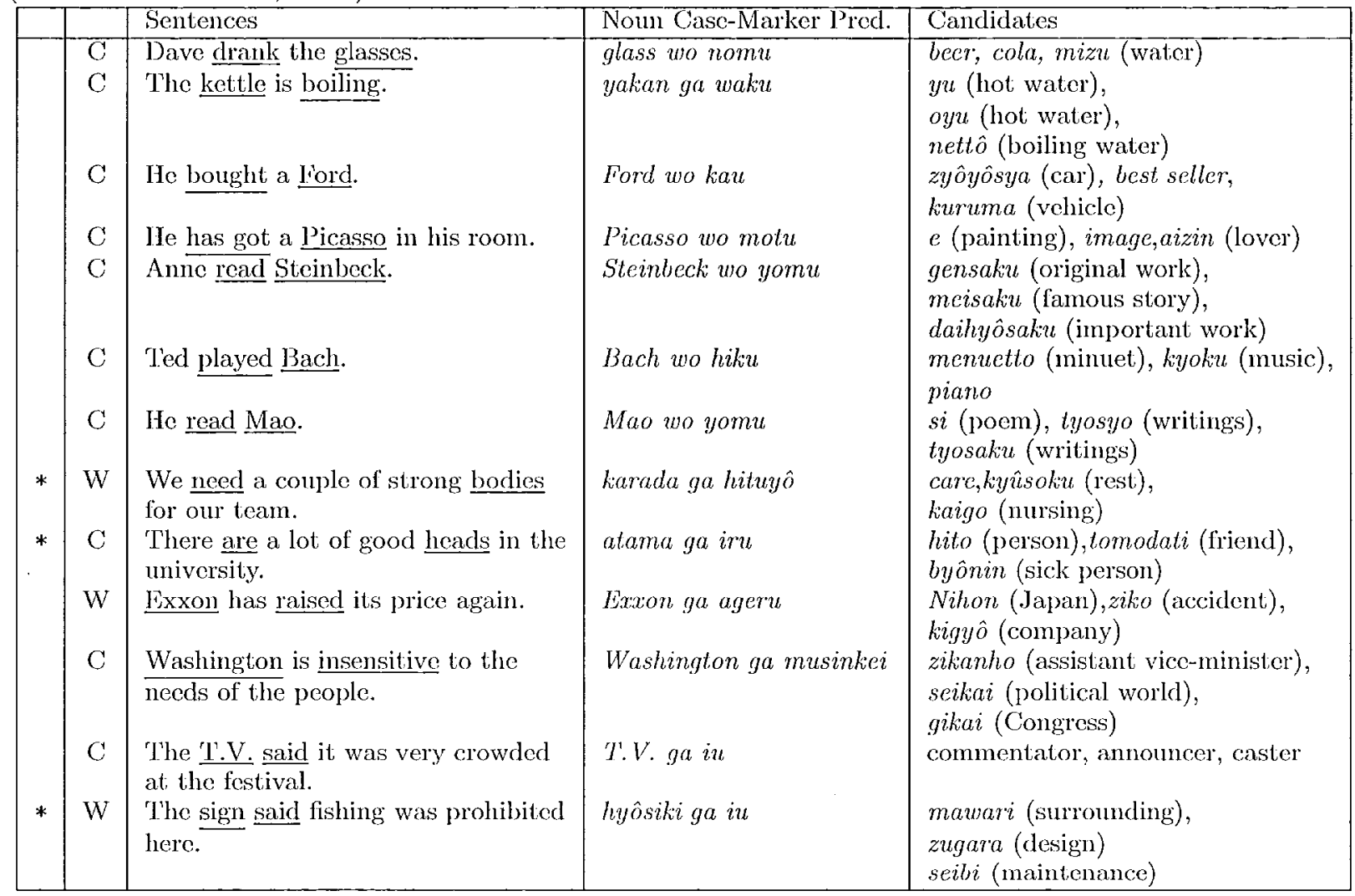

\section{Discussion}

Semantic Relation The method proposed in this paper identifies implicit terms for the explicit term in a metonymy. However, it is not concorned with the semantic relation between an explicit term and implicit term, because such semantic relations are not directly expressed in corpora, i.e. noun phrases of the form $A$ no $B$ can be found in corpora but their semantic relations are not. If we need such semantic relations, we must semantically analyze the noun phrases (Kurohashi and Sakai, 1999).

Applicability to other languages Japanese noun phrases of the form $A$ no $B$ are specific: to Japanese. The proposed method, however, could easily be extended to other languages. For cxample, in English, noun phrases $B$ of $A$ could be used to extract semantically related nouns. Nouns related by is-a relations or part-of relations could also be extracted from corpora (Hearst, 1992; Berland and Charniak, 1999). If such semantically related nouns are extracted, then they can be ranked according to the measure $M$ definod in Equation (3).

Lexically based approaches Gencrative Lexicon theory (Pustejovsky, 1995) proposed the qualia structure which encodes semantic relations among words explicitly. It is useful to infer an implicit term of the explicit term in a metonymy. The proposed approach, on the other hand, uses corpora to infer implicit terms and thus sidesteps the construction of qualia structure. $^{8}$

\section{Conclusion}

This paper discussed a statistical approach to the interpretation of metonymy. The method follows the procedure described below to interpret a metonymy in Japanese:

1. Given a metonymy of the form 'Nom $A$

\footnotetext{
${ }^{8}$ Briscoc et al. (1990) discusses the use of machinereadable dictionaries and corpora for acquiring lexical semantic information.
} 
Case-Marker $R$ Predicate $V$ ', nouns that are syntactically related to the explicit torm $A$ are extracted from a corpus.

2. 'The extracted nouns are ranked according to their degree of appropriateness as interpretations of the metonymy by applying a statistical measure.

'The method has been tested exporimentally. Fifty-three out of seventy-five metonymies were correctly interpreted. This is quite a promising first step toward the statistical processing of metonymy.

\section{References}

Matthew Berland and Eugene Charniak. 1999. Finding parts in very large corpora. In $A C L$ 99 , pages $57 \cdot 64$.

Jacques Bouaud, Bruno Bachindont, and Pierre Zweigenbaum. 1996. Processing nnctonyny: a domain-model heuristic graph traversal ap)proach. In COLING-96, pages $137-142$.

'Ted Briscoe, Ann Copestake, and Bran Bognracv. 1990. Enjoy the paper: Lexical scmantics via lexicology. In COLING-90, pages $42 \ldots$ 47.

Peter F. Brown, Vincent J. Della Pictra, Peter V. deSoura, Jenifer C. Ial, and Robert I. Mercer. 1992. Class-based n-gram models of natural linguage. Computational Linguistics, 18(4):467 4.79.

Kenneth Ward Church and Patrick Hanks. 1990. Word association norms, mutual information, and lexicograplyy. Computational Linguistics, 16(1):22-29.

Dan Fass. 1988. Metonymy and metaphor: What's the difference? In COLING-88, pages 177-181.

Dan Fass. 1997. Processing Metonymy and Metaphor, volume 1 of Contemporary Studies in Cognitive Science and T'echnology. Ablex Publishing Corporation.

Stephane Ferrari. 1996. Using textual clues to improve metaphor processing. In $A C L-96$, pages $351-354$.

Marti A. Hearst. 1992. Automatic acquisition of liyponyms from large text corpora. In COLING-92, pages 539-545.

Exic Iverson and Stephen Helmreich. 1992. Metallel: An integrated approach to non- literal phrase interpretation. Computational Intelligence, 8(3):477-493.

Shin-ichiro Kamci and Takahiro Wakao. 1992. Metonymy: Reassessment, survey of acceptability,and its treatmont in a machine translation systcm. In $A C L-92$, pages 309-311.

Sadao Kurohashi and Yasuyuki Sakai. 1999. Somantic analysis of Japanese noun phrases: A new approach to dictionary-based understanding. In $A C L-99$, pages $481-488$.

Takashi Kusumi. 1995. Hiyu-no Syori-Kateito Imi-Kôzô (Processing and Semantic Structure of 'Iropes). Kazama Publisher. (in Japanese).

George Lakoff and Mark Johnson. 1980. Metaphors We Live By. Clicago University Press.

Christopher D. Mamning and Hinrich Schïtzo, 1999. Foundations of Statistical Natural Language Processing, chapter 6. The MrI' Press.

Yuji Matsumoto, Akira Kitauchi, Tatsuo Yamashita, and Yoshitaka Hirano. 1999. Japanese morphological analysis system Chasen mamual. Nara Institute of Science and 'l'celmology.

Masaki Murata, Hitoshi Isalnaja, and Makoto Nagao. 1999. Resolution of indirect anaphora in Japanese sentences using examples "X no $\mathrm{Y}(\mathrm{X}$ of $\mathrm{Y})$ ". In ACL'g9 Workshop on Goreference and Its Applications, pages 31-38.

Jannes 1'ustejovsky. 1995. The Generative Lexicon. 'The MI'J' Press.

I'he National Langtage Research Institute. 1996. Bunrui Goi-hyô 7jôho-ban(Taxonomy of Japanese, enlarged edition). (in Japancse).

Atsimmu Yamamoto, Masaki Murata, and Makoto Nagao. 1998. Example-based metonymy interpretation. In Proc. of the 4th Annual Meeting of the Association for. Natural Language Processing, pages 606-609. (in Japanese).

Masa-aki Yamanashi. 1988. Hiyu-to Rikai (Tropes and Understanding). Tokyo University Publisher. (in Japanese).

Masa-aki Yamanashi. 1995. Ninti Bunpồ-ron (Cognitive Linguistics). Hitsuji Publisher. (in Japanese). 